\title{
Is inhaled ammonia neurotoxic?
}

Is inhaled ammonia neurotoxic?

\author{
Kaye H. Kilburn
}

University of Southern California, Los Angeles, California, USA

Keywords Toxicology, Gas

Abstract Describes how a large ammonia release exposed about 150 nearby residents to this irritating gas and sent seven to hospital emergency rooms. Six weeks later the 41 most symptomatic people completed questionnaires and had physical examinations. The 12 most impaired had subsequent neurobehavioral testing to see if exogenous ammonia was toxic to the brain as is endogenous ammonia in hepatic coma. Spirometry was used to test pulmonary function. Frequencies of 35 symptoms were obtained by questionnaire, as were medical, respiratory and neuropsychiatric histories and data on previous chemical exposures. Comparisons were made with unexposed subjects after adjusting for age, sex, educational level and other determining factors. The exposed group's mean values were significantly abnormal for simple and choice reaction, balance with eyes open, color discrimination, visual field performance in both eyes and hearing. Also abnormal were cognitive performance on Culture Fair, digit symbol, vocabulary and delayed but not immediate verbal recall. Making trails $A$ and $B$ was slow and fingertip number writing had excessive errors. Spirometric measurements were normal. Confounding features and biases were minimal. Exposure to ammonia, for a few minutes to several hours, was associated with neurobehavioral impairment measured after 22 months. Thus inhaled ammonia shares the toxicity of endogenous ammonia. Effects were persistent and are probably permanent.

\section{Introduction}

This pungent, colorless gas has a low vapor pressure, 0.597, and is highly soluble in water, forming ammonium hydroxide. The gas is easily liquified and since the late nineteenth century it has been utilized as a refrigerant in largescale cold storage plants. Toxicity for skin, eyes, and respiratory tract have been described since 1887 (Hunter, 1968; Arwood et al., 1985). In 1941, 75 people were poisoned in the cellars of a London brewery when a steel splinter pierced an ammonia condenser that leaked during an air raid (Caplin, 1941). They presented with evidence of irritated mucous membranes, chest tightness and persistent cough. In addition, shock, restlessness and distress were seen in those severely affected. Within two days they had ulcers and erosions of conjunctival and cornea, nose, mouth, trachea, and had developed bronchitis and bronchiolar pneumonia; many died. The fate of the survivors was not determined. Earlier Slot (1938) had reported anxiety, neurosis and resultant disability that lasted long after patients recovered physically. One of six patients who sought help for depression and lassitude also complained of disordered taste of food (Walton, 1973).

The importance of ammonia in producing hepatic coma should have aroused concern for neurological derangement, acutely and in survivors of these and

Examination and testing were sponsored by attorneys.
239

Submitted February

1999

Accepted April 1999
Environmental Management and

Health, Vol. 11 No. 3, 2000, pp. 239-249. (C) MCB University 
$\mathrm{EMH}$

11,3

240 similar exposures (Zieve et al., 1974a; Adams and Victor, 1989; Cooper and Plum, 1987). Endogenous ammonia from hepatic failure, especially in patients with alcoholic liver disease and cirrhosis, causes progressive neurological failure and finally coma (Zeive et al., 1974a, b; Dejong et al., 1996). Recovery is exceptional, as much of the syndrome is irreversible. Inhaled ammonia burns the respiratory tract and causes death by bronchiolitis (Sobonya, 1977; Montague and Macneil, 1980).

In this incident, 60lbs or more of ammonia were released from a commercial cold storage plant into the neighborhood. More than 150 persons were affected and evacuated and 12 had persistent medical problems that were studied 22 months after exposure.

\section{Methods}

A family practitioner examined 41 patients for persistently inflamed eyes, noses and throats, respiratory burning, SOB, irritation, headache, nausea about six weeks after the ammonia exposure. Seven of these had been seen in emergency rooms on the the night when the ammonia escaped. Over 150 people were symptomatic after exposure. Twelve of the 41 were selected for neurobehavioral testing 22 months later. Their test scores were compared with 308 referent subjects who had been picked from random phone calls from voter registration records in three areas of the country (Arizona, Louisiana, Tennessee), screened to exclude chemical exposures, tested for performance and prediction equations calculated. Referent subjects were reimbursed for their time and mileage.

Examiners of the 308 were blinded as to subjects' exposure status, as referents and exposed were tested together. Exposed status for the 12 was known to the examiners. All subjects gave informed consent and the protocol was approved by the Human Studies Research Committee of the University of Southern California School of Medicine.

\section{Exposure}

Reconstruction of the incident showed that at about 6.30 p.m. a gauge broke on a pipe in the ammonia condenser, permitting ammonia at 4.1atm (601b/sq.ft) to escape into a residential neighborhood. It was estimated that ammonia concentrations of 200 parts per million (ppm) were reached 700 meters $(2,000$ feet) from the broken pipe (The JL, 1997). The escape duration was 2.5 hours. Ammonia concentrations of $24 \mathrm{ppm}$ were measured 16 meters downwind at 2.20 a.m. by a Hazmat team. After a second leak at about 6.30 a.m., levels were $20 \mathrm{ppm}$ at this site.

Subjects completed questionnaires which were checked by computer. Included were the frequencies of 35 common health complaints (Kilburn et al., 1987, 1989) the American Rheumatism Association lupus erythematosus questions (Levin et al., 1984), a standard respiratory questionnaire (Ferris, 1978), histories of occupational and other exposures to chemicals, pesticides and herbicides, tobacco, alcohol and drug use (prescription and illicit), 
unconsciousness, anesthesia, and head trauma and neurological and medical histories (Kilburn et al., 1989). The questionnaires and the neurophysiological and neuropsychological test battery had evolved through studies of histology technicians (Kilburn et al., 1987), firemen exposed to thermolysis products of PCBs (Kilburn et al., 1989), a TCE solvent exposed population (Kilburn and Warshaw, 1993), people exposed to toluene-rich chemical waste and matched groups of unexposed reference subjects (Kilburn and Warshaw, 1995). Alcohol was measured in air expired after a 20-second breath hold using a fuel cell analyzer which is equivalent to blood alcohol level.

\section{Neurophysiological tests}

Simple reaction time and visual two-choice reaction time were measured with a computerized instrument (Miller et al., 1989). Body balance was measured with the subject standing erect with feet together. The position of the head was tracked by two microphones from a sound-generating stylus on a head-band, processed in a computer and expressed as mean speed of sway in $\mathrm{cm} / \mathrm{sec}$ (Kilburn and Warshaw, 1994).

The minimal sway speed of three consecutive 20-second trials was counted for sway with eyes open and with eyes closed. The blink reflex was measured with surface electromyographic electrodes (EMG) from lateral orbicularis oculi muscles bilaterally (Shahani and Young, 1982; Warshaw et al., 1992) after tapping the right and left supraorbital notches with a light hammer which triggered a recording computer. Ten firings of R-1 and of the volley of second waves, R-2 were averaged to find the mean response for each site and failures were recorded (Shahani and Young, 1982). Color discrimination was measured with the desaturated (Lanthony, 1978) 15-hue test under constant illumination and scored by the method of Bowman (1982). Hearing was measured in left and right ears with standard audiometers (model ML-AM Microaudiometrics, So. Daytona, FL) at stepped frequencies of 500 to 8,000Hertz. The sum of deficits in both ears was the hearing score.

Threshold testing of visual fields used a computerized Med Lab Technology automated perimeter recording to a computer which mapped the central $30^{\circ}$ of right and left eyes individually of all adults.

\section{Neuropsychological tests}

Immediate and delayed verbal recall was measured using two stories from Wechsler's Memory Scale (revised 1987). Culture Fair (battery 2A) and vocabulary were done in groups. Culture Fair tested non-verbal, nonarithmetical intelligence based on the selection of designs for similarity, difference, completion and pattern recognition and transfer (Cattell, 1951; Cattell et al., 1941). Culture Fair resembles Raven's progressive matrices (Raven et al., 1988). The 46-word vocabulary test was from the multidimensional aptitude battery (Jackson, 1985).

Digit symbol from the Wechsler Adult Intelligence Scale-revised (WAIS-R, 1987) tested attention and integrative capacity. Information, picture completion

Is inhaled ammonia neurotoxic? 
$\mathrm{EMH}$

11,3

242 and similarities, also from the WAIS-R, tested embedded memory. Time needed to place 25 pegs in the Lafayette slotted pegboard was measured. Trail making $\mathrm{A}$ and $\mathrm{B}$ and fingertip number writing which measure dexterity, coordination, decision making and peripheral sensation and discrimination were from the Halstead-Reitan battery (Reitan, 1966, 1990).

Subjects' moods were appraised by responses to 65 terms describing emotional status for the week using the profile of mood states (POMS) (McNair et al., 1971, 1989). Surrogates for exposure including recall of their times in the gas cloud and the distance from leak site as approximations for dose bore no relationship to testing scores.

\section{Statistical analysis}

All scores and computed data for sway, blink, reaction time and visual fields were entered into a 486 IBM PC compatible computer. Descriptive and analytical computations included analysis of variance (ANOVA), and analysis of covariance (ANOCVA) which adjusted for differences in age, education, gender and height and having completed five years less school; so covariance analysis was used to adjust comparisons. All test results were treated as dependent variables. Stepwise linear regression modeling used Stata Statistical Software (Stata Corporation, 1993)[1]. No other independent factors, including family income, hours of general anesthesia, body weight and POMS score, had significant coefficients for any dependent variable. Increased age reduced all test scores except for vocabulary. More years of schooling were associated with better psychological tests scores. Statistical significance was defined as $p<$ 0.05 .

To compare individuals in the group, the sum of abnormal test scores, defined as outside 1.5 times the standard deviation, was computed. This definition selects as abnormal the scores of 3 to 9 percent, average 5 percent of subjects who were not exposed to adverse chemicals (Table I).

\begin{tabular}{ccccc}
\hline Subject & Age & Abnormal tests & POMS scores & $\begin{array}{c}\text { Symptom } \\
\text { frequencies }\end{array}$ \\
\hline 1 & 63 & 3 & 21 & 6.8 \\
2 & 15 & 3 & 8 & 1.2 \\
3 & 39 & 4 & 28 & 2.0 \\
4 & 17 & 5 & 1 & 2.1 \\
5 & 75 & 6 & 59 & 1.2 \\
6 & 23 & 8 & 81 & 2.5 \\
7 & 37 & 10 & 93 & 2.4 \\
8 & 39 & 11 & 10 & 1.8 \\
9 & 55 & 14 & 26 & 1.5 \\
10 & 40 & 14 & 11 & 4.7 \\
11 & 62 & 15 & 34 & 2.1 \\
12 & 13 & 17 & 30 & 2.2 \\
\end{tabular}

$$
\text { subjects who were not exposed to adverse chemicals (Table I). }
$$

Table I.

Neurobehavioral test abnormalities, age, POMS scores and symptom frequencies 


\section{Results}

The exposed subjects were slightly older, at 48.1 years, than were the unexposed referents (46.6 years) which was not significant, but their educational attainment was significantly less (Table II). In view of this and to adjust for variation in age distribution in this small group, comparisons were made of exposed subjects' scores to their calculated predicted values that adjusted for age, sex, education and other factors applicable, i.e. height for balance with eyes closed and body mass-index for finger tip number writing errors.

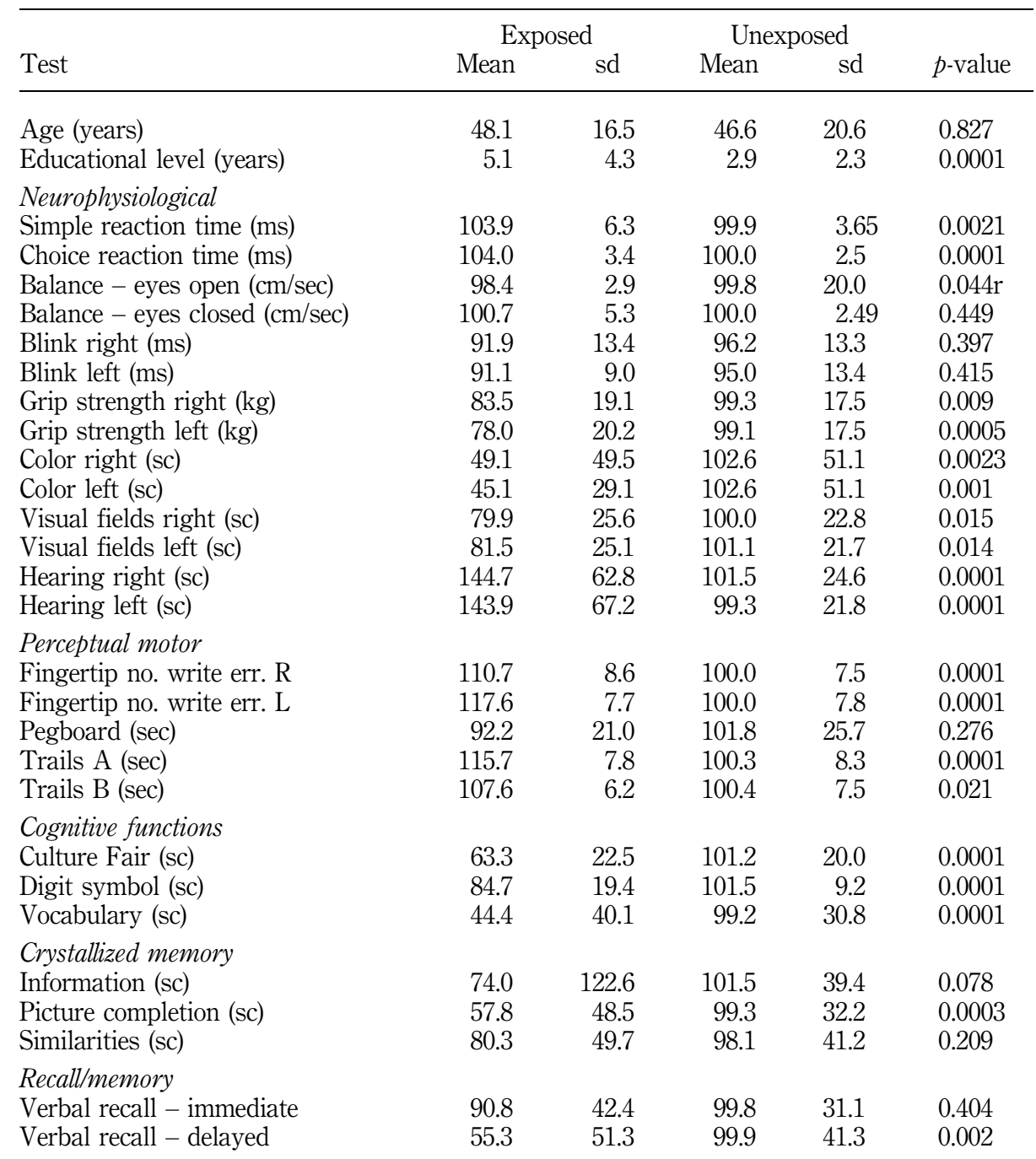

Notes: $\mathrm{cm} / \mathrm{s}=$ centimeter per second; $\mathrm{s}=$ second; $\mathrm{ms}=$ millisecond; $\mathrm{sc}=$ score; $\mathrm{r}=$ reversed
Is inhaled ammonia neurotoxic?
Table II. Neurobehavioral test scores for 12 ammonia exposed La Habra, CA subjects compared with predicted values of unexposed subjects. Means and standard deviations (sd) with $p$-values 
$\mathrm{EMH}$

11,3

\section{4}

\section{Physiological functions}

Simple and choice reaction time were significantly below predicted (Table I). Balance with the eyes open and with the eyes closed was not abnormal. Grip was diminished but blink reflex latency was unaffected. Color discrimination and visual field performance were reduced for both eyes. Hearing was significantly below predicted for both ears.

\section{Psychological tests}

Cognitive performance was reduced for Culture Fair, digit symbol and vocabulary. Perceptual motor test showed that trail making A and B slowed, peg placement was normal but errors were increased for fingertip number writing. Verbal recall, immediate, was not significantly reduced but 30-minute recall was decreased. Cultural awareness as tested with information and similarities was intact but not picture completion. This was consistent with school grade attainment and the group being normal prior to the ammonia exposure.

The 12 exposed subjects had three to 17 abnormalities (Table II). The highest scores were in a woman at some distance from the site of ammonia release, and one of four members of a nearby exposed family. The sum of abnormalities did not associate with the mood state score or the frequency of symptoms by using regression analysis.

Pulmonary function tests, including forced vital capacity and flows, were not decreased and equaled the predicted values that were adjusted for effects of age, sex, height, and years of cigarette smoking (Table III).

\section{Discussion}

This appears to be the first study of neurobehavioral impairment following inhalation of ammonia. It is a collection of patients in whom persistence of complaints was the criterion for stepwise triage. This manner of selecting groups has been used in clinical medicine for centuries and defines a population for study. Comparison of these exposed subjects individually to predicted values is logical and practical. The group's subsequent comparison with an unexposed group showed statistically significant differences. Strength of association was high, as all these people and none of the control subjects had been exposed to ammonia. Intensity of exposure had caused a mass evacuation

Table III.

Pulmonary function tests as percent predicted

\begin{tabular}{lccccc}
\hline & \multicolumn{2}{c}{ Ammonia } & \multicolumn{2}{c}{ Unexposed } & \\
& Mean & sd & Mean & sd & $p$-value \\
\hline FVC & 108.0 & 24.9 & 101.6 & 15.1 & 0.233 \\
FEV $_{1}$ & 104.0 & 26.3 & 93.6 & 15.8 & 0.064 \\
FEF25-75 $_{\text {FEF75-85 }}$ & 102.6 & 42.6 & 88.1 & 35.0 & 0.231 \\
FEV $_{1}$ /FVC & 99.9 & 50.6 & 78.1 & 52.7 & 0.225 \\
& 83.5 & 2.3 & 82.8 & 2.8 & 0.450 \\
\hline
\end{tabular}


and sent these subjects to emergency rooms. Exposure duration varied from 20 minutes to several hours for the first episode and perhaps two hours for the second episode.

The specificity seems clear; only ammonia was released. The toxicity of ammonia for the brain, the endogenous ammonia from hepatic failure, is wellknown. The history of adverse health effects from ammonia goes back to 1897 (Hunter, 1968).

These coherent and plausible findings should be confirmed by additional observations. The author compared these 12 people with neurobehavioral impairment with findings in a worker overcome in an open field by an ammonia cloud from a chemical plant and in a mother and daughter exposed when anhydrous ammonia was inadvertently dumped in front of their home. Thus far, no animal model for subtle neurobehavioral effects has been developed.

Obviously additional observations of exposed human subjects are needed. They must be studied with sensitive methods as were used here. Cautious interpretation is advised until findings are confirmed. Meanwhile massive releases appear to be unduly hazardous. Thus the warning flag is up. Every effort should be made to protect workers and neighbors from ammonia during its generation, transport, use as a refrigerant and in chemical manufacturing. It is wrong to regard all concentrations of ammonia as non-toxic just because low concentrations of ammonia water seem safe for household cleaning.

Ammonia burns the moist surfaces of the eyes and respiratory tract and has caused deaths from bronchopneumonia. Two fatalities - a 33-year old man and a 51-year old - had corneal and skin burns, respiratory distress, sloughed the lining of their airways, received tracheotomies and died with oliguria and pneumonia. Pathological diagnosis confirmed purulent exudate in the smaller bronchi and incipient fibrosis in the alveoli. Ammonia hydrates exothermically, so the burns can be thermal as well as chemical. Bronchiectasis has been diagnosed in survivors (Kass et al., 1972; Montague and MacNeil, 1980).

There is a slight reservation about comparing Hispanic exposed people to Caucasian reference subjects. However, no significant differences were demonstrated between these two groups in the only large study that compared Hispanics with Caucasians using this battery of tests (Kilburn and Thornton, 1995).

The abnormalities of reaction time, color discrimination, visual fields, and hearing are explained better by generalized brain damage than damage at several different sites. The damage had persisted for 22 months so any spontaneous improvements had occurred. Unexpectedly, balance with eyes open and with eyes closed was normal, consistent with each other and appeared valid. Careful review of these data did not show outliers or statistical oddities but the small sample size may be responsible.

Is inhaled ammonia neurotoxic? 
$\mathrm{EMH}$

11,3

246
The neuropsychological deficits including for cognitive function, perceptual motor speed, recall and cultural information, were also consistent with diminished brain function. A literature review found references to depression, lassitude and cacosmia but no descriptions of neurobehavioral evaluations.

Only two studies of inhaled ammonia were found in a review of ammonia references (Ferguson et al., 1977; Hatton et al., 1979). One study included five men and one woman who worked in an Allied Chemical Company, Morristown, New Jersey. To avoid misunderstanding, it is reviewed in detail (Ferguson $e t$ al., 1977).

The six subjects were employees and were "acclimatized" to levels of ammonia up to 400 to $500 \mathrm{ppm}$. They were members of an unusually healthy and long-lived group of workers, according to the authors. At this site, workers were exposed to ammonia after 1887. Continuous exposures as high as 150 to $200 \mathrm{ppm}$ were common. Thus the six subjects observed for physiological effects had had 1.5 to 22 years of work day exposures to ammonia. They were exposed six hours a day, five days a week, for six weeks and showed no physiological alterations of pulse, respiration or blood pressure, as the dose was increased from 0 to 25, 50, 100 and 150ppm. Only eye irritation increased. Unfortunately, central nervous system functions were not evaluated.

Four children were exposed to ammonia when a tank truck fell from an overpass on to the highway below and burst. One was in coma, another was lethargic and two had abnormal electroencephalographs showing encephalopathy (Hatton et al., 1979). They all survived.

In contrast to the paucity of data concerning inhalational effects on the central nervous system (CNS), there are numerous descriptions of the CNS effects of endogenous ammonia in hepatocellular failure, and hepatic coma including hereditary hyperammoniac syndromes of childhood. In these disorders, hepatic coma is dense when the blood ammonia is elevated and lightens when levels are lowered, supporting the theory that ammonia intoxication is responsible (Adams and Victor, 1989; Cooper and Plum, 1987; Zieve et al., 1974a, b; Zieve and Olson, 1977; Zieve, 1981, 1987).

The pathology of the human brain after severe hepatic encephalopathy includes chronic astrocytic proliferation producing Alzheimer's type II cells (Cooper and Plum 1987; Szerb and Butterworth, 1992). The globus pallidus has enhanced contrast using the T1-weighted magnetic resonance imaging (Taylor-Robinson et al., 1995; Behar et al., 1993). Brains analyzed from patients dying of hepatic coma showed high levels of glutamine and deficiencies of glutamate, suggesting that release of glutamine from glutamate occurs when the brain's ammonia is elevated (Butterworth et al., 1987). There are other manifestations of an abnormal urea cycle. One observation that may be applicable to future studies is the detection of glutamate/glutamine resonance by $1 \mathrm{H}$ magnetic spectrometry (Prost et al., 1997).

These threads of evidence braid into a coherent picture that puts the astrocyte in the center of responses to ammonia whatever its source; failure of urea formation in the liver or inhalation. In summary, it is tentatively 
concluded that inhaled ammonia produces encephalopathy. The concentrations and durations required cannot be estimated. Exposures of volunteer human subjects to ammonia would be unethical in light of this report. Ammonia resembles inhaled chlorine in producing damage (Kilburn, 1995). The observations suggest that ammonia production, its use as a refrigerant and as a fertilizer should be located away from people, so that they are not at risk from brain damage and death.

\section{Is inhaled ammonia neurotoxic?}

\section{Note}

1. Stata Corporation, 702 University Drive East, College Station, TX 77840, USA.

\section{References}

Adams, R. and Victor, M. (1989), Principles of Neurology, 4th ed., McGraw-Hill, New York, NY, pp. 853-5.

Arwood, R., Hammond, J. and Ward, G. (1985), “Ammonia inhalation”, Journal of Trauma, Vol. 25, pp. 444-7.

Behar, K.L., Fitzpatrick, S.M., Hetherington, H.P. and Shulman, R.G. (1993), "Cerebral metabolic studies in vivo by combined $1 \mathrm{H} / 31 \mathrm{P}$ and $1 \mathrm{H} / 13 \mathrm{C}$ NMR spectroscopic methods", Acta Neurochir. Suppl., Vol. 57, pp. 9-20.

Bowman, B.J. (1982), “A method for quantitative scoring of the Farnsworth panel D-15”, Acta Ophth., Vol. 60, pp. 907-16.

Butterworth, R.F., Lavoie, J., Giguere, J.F. and Layrargues, G.P. (1987), "Cerebral GABA-ergic and glutamatergic function in hepatic encephalopathy", Neurochem. Pathol., Vol. 6 Nos 1-2, pp. 131-44.

Caplin, M. (1941), “Ammonia-gas poisoning - 47 cases in a London shelter”, Lancet, Vol. 2, pp. 295-6.

Cattell, R.B. (1951), "Classical and standard score IQ standardization of the IPAT: culture free intelligence scale 2", J. Consulting Psych., Vol. 15, pp. 154-9.

Cattell, R.B., Feingold, S.N. and Sarason, S.B. (1941), "A culture free intelligence test II evaluation of cultural influences on test performance”, J. Educational Psych., Vol. 32, pp. 81-100.

Cooper, A.J.L. and Plum, F. (1987), "Biochemistry and physiology of brain ammonia", Physical Rev., Vol. 67, pp. 440-519.

Dejong, C.H., Deutz, N. and Soeters, P.B. (1996), "Ammonia and glutamine metabolism during liver insufficiency: the role of kidney and brain in interorgan nitrogen exchange", Scand. J. Gastroenterol. (Suppl.), Vol. 28, pp. 61-77.

Ferguson, W.S., Coch, W.C., Webster, L.B. and Gould, J.R. (1977), "Human physiological response and adaption to ammonia”, J. Occupat. Med., Vol. 19 No. 5, pp. 319-26.

Ferris, B.G. Jr (1978), "Epidemiology standardization project”, Am. Rev. Resp. Dis., Vol. 118, pp. $7-54$.

Hatton, D.V., Leach, C.S., Beaudet, A.L., Dillman, R.O. and DiFerrante, N. (1979), "Collagen breakdown and ammonia inhalation", Arch. Environ. Health, Vol. 34, pp. 83-7.

Hunter, D. (1968), Diseases of Occupations, 4th ed., Edward Arnold, London.

Jackson, D.N. (1985), Multidimensional Aptitude Battery, Sigma Assessments Systems, Inc., Port Huron, MI.

Kass, Z.N., Dobry, C.A. and Holzer, M. (1972), "Bronchetiasis following ammonia burns of the respiratory tract”, Chest, Vol. 62, pp. 282-5. 
$\mathrm{EMH}$

11,3

248
Kilburn, K.H. (1995), "Evidence that inhaled chlorine is neurotoxic and causes airways obstruction”, Intl J. Occup. Med. \& Tox., Vol. 5, pp. 267-76.

Kilburn, K.H. and Thornton, J.C. (1995), "Protracted neurotoxicity from chlordane sprayed to kill termites”, Env. Health Resp., Vol. 103, p. 690.

Kilburn, K.H. and Warshaw, R.H. (1993), "Neurobehavioral testing of subjects exposed residentially to groundwater contaminated from an aluminum die-casting plant and local referents”, J. Toxicol. \& Environ. Health, Vol. 39, pp. 483-96.

Kilburn, K.H. and Warshaw, R.H. (1994), "Balance measured by head (and trunk) tracking and a force platform in chemically (PCB and TCE) exposed and referent subjects", Occup. Environ. Med., Vol. 5, pp. 381-5.

Kilburn, K.H. and Warshaw, R.H. (1995), "Neurotoxic effects from residential exposure to chemicals from an oil reprocessing facility and Superfund site", Neurotox. \& Teratol., Vol. 17, pp. 89-102.

Kilburn, K.H., Warshaw, R.H. and Shields, M.G. (1989), "Neurobehavioral dysfunction in firemen exposed to polychlorinated biphenyls (PCBs): possible improvement after detoxification”, Arch. Environ. Health, Vol. 44, pp. 345-50.

Kilburn, K.H., Warshaw, R.H. and Thornton, J.C. (1987), "Formaldehyde impairs memory, equilibrium, and dexterity in histology technicians: effects which persist for days after exposure", Arch. Environ. Health, Vol. 42, pp. 117-20.

Lanthony, P. (1978), "The desaturated panel D-15”, Doc. Ophthalmol., Vol. 46, pp. 185-9.

Levin, R.E., Weinstein, A., Peterson, M. et al. (1984), "A comparison of the sensitivity of the 1971 and 1982 American Rheumatism Association criteria for the classification of lupus erythematosus", Arthritis \& Rheum., Vol. 27, pp. 530-38.

McNair, D.M., Lorr, M. and Droppleman, L.F. (1971/1989), Profile of Mood States, Educational and Industrial Testing Service, San Diego, CA.

Miller, J.A., Cohen, G.S., Warshaw, R. et al. (1989), "Choice (CRT) and simple reaction times (SRT) compared in laboratory technicians: factors influencing reaction times and a predictive model", Am. J. Indust. Med., Vol. 15, pp. 687-97.

Montague, T.J. and Macneil (1980), “Mass ammonia inhalation”, Chest, Vol. 77, pp. 496-8.

Prost, R.W., Mark, L., Mewissen, M. and Li, S.H. (1997), "Detection of glutamate/glutamine resonances by $1 \mathrm{H}$ magnetic resonance spectroscopy at 0.5 tesla", Magn. Reson Med., Vol. 37 No. 4, pp. 615-18.

Raven, J.C., Court, J.H. and Raven, J. (1988), Standard Progressive Matrices, Oxford Psychologists Press, Oxford.

Reitan, R.M. (1966), "A research program on the psychological effects of brain lesions in human beings”, in Ellis, N.R. (Ed.), International Review of Research in Mental Retardation, Academic Press, New York, NY, pp. 153-216.

Reitan, R.M. (1990), "Validity of the trail-making test as an indicator of organic brain damage", Percept. Motor Skills, Vol. 1958 No. 8, pp. 271-6.

Shahani, B.T. and Young, R.R. (1982), "Human orbicularis oculi reflexes", Neurology (NY), Vol. 22, pp. 149-54.

Slot, G.M.J. (1938), “Ammonia gas burns; an account of six cases”, Lancet, Vol. 2, pp. 1356-7.

Sobonya, R. (1977), "Fatal anhydrous ammonia inhalation”, Human Path., Vol. 8, pp. 293-9.

Szerb, J.C. and Butterworth, R.F. (1992), "Effects of ammonium ions on synaptic transmission in the mammalian central nervous system”, Prog. Neurobiol., Vol. 39 No. 2, pp. 135-53.

Taylor-Robinson, S.D., Oatridge, A., Hajnal, J.V., Burroughs, A.K., McIntyre, N. and deSouza, N.M. (1995), "MR imaging of the basal ganglia in chronic liver disease: correlation of T1- 
weighted and magnetization transfer contrast measurements with liver dysfunction and neuropsychiatric status”, Metab. Brain Dis., Vol. 10 No. 2, pp. 175-88.

The JL (1997), Air Dissipation Monitoring: A Visual Approach, Waterloo, ON.

Walton, M. (1973), "Industrial ammonia gassing”, Brit. J. Industr. Med., Vol. 30, pp. 78-86.

Warshaw, R.H., Hanscom, B. and Kilburn, K.H. (1992), "A reproducible trigger for measurement of trigeminal latencies elicited by a glabellar tap”, Environ. Res., Vol. 60, pp. 328-31.

Zieve, F.J., Zieve, L., Doizaki, W.M. and Gilsdorf, R.B. (1974a), "Synergism between ammonia and fatty acids in the production of coma: implications for hepatic coma", J. Pharmacol. Exp. Ther., Vol. 191, pp. 10-16.

Zieve, L. (1981), "Synergism among toxic factors and other endogenous abnormalities in hepatic encephalopathy", in Brunner, G. and Schmidt, F.W. (Eds), Artficial Liver Support, Springer-Verlag, New York, NY, pp. 18-24.

Zieve, L. (1987), "Pathogens of hepatic encephalopathy", Metab. Brain Dis., Vol. 2, pp. 147-65.

Zieve, L. and Olsen, R.L. (1977), "Can hepatic coma be caused by a reduction in brain non-adrenaline or dopamine?”, Gut, Vol. 18, pp. 688-91.

Zieve, L., Dorizaki, W.M. and Zieve, F.J. (1974b), "Synergism between mercaptans and ammonia or fatty acids in the production of coma: a possible role for mercaptans in the pathogenesis of hepatic coma”, J. Lab. Clin. Med., Vol. 83, pp. 16-28.

\section{Further reading}

Brusilow, S.W. (1995), "Urea cycle disorders: clinical paradigm of hyperammonemic encephalopathy”, Prog. Liver Dis., Vol. 13, pp. 293-309.

Durate, J., Macias, S., Coria, F., Fernandez, E. and Claverila, L. (1993), "Valproate-induced coma: case report and literature review”, Ann. Pharmacother., Vol. 27 No. 5, p. 582.

Ko, F.J., Chiang, C.H., Liu, W.J. and Chiang, W. (1993), "Alteration of amino acid in plasma and cerebrospinal fluid of children with seizure disorders", Kaohsiung J. Med. Sci., Vol. 9 No. 3, pp. 131-42.

Lee, J.C., Lai, H.S., Huang, S.M., Chang, C.J., Wang, S.T. and Chen, W.J. (1994), “Hyperammonemic encephalopathy due to essential amino acid hyperalimentation”, J. Formos. Med. Assoc., Vol. 93 No. 6, pp. 486-92.

Levy, D.M., Divertie, M.B., Litzow, T. and Henderson, J.W. (1964), “Ammonia burns of the face and respiratory tract”, JAMA, Vol. 190 No. 10, pp. 95-8.

Matsuoka, M. and Igisu, H. (1993), "Comparison of the effects of L-carnitine, D-carnitine and acetyl-L-carnitine on the neurotoxicity of ammonia”, Biochem. Pharmacol., Vol. 46 No. 1, pp. 159-64.

Miller, A., Thornton, J.C., Warshaw, R. et al. (1986), "Mean and instantaneous expiratory flows, $\mathrm{FVC}$ and $\mathrm{FEV}_{1}$ : prediction equations from a probability sample of Michigan, a large industrial state", Bull. Eur. Physiopathol. Respir., Vol. 22, pp. 587-97.

Norenberg, M.D. (1987), "The role of astrocytes in hepatic encephalopathy", Neurochem. Pathol., Vol. 6 Nos 1-2, pp. 13-33.

Wechsler, D. (1945), “A standardized memory scale for clinical use”, WMS-revised (1987), J. Psychol., Vol. 19, pp. 87-95.

Wechsler, D. (1981), Adult Intelligence Scale Manual - Revised, The Psychological Corporation, New York, NY.

Yamazaki, S., Fukui, K., Kawashima, H., Kuge, Y., Miyake, Y. and Kangawa, K. (1996), "Uptake of radioactive octamoate in astrocytoma cells: basic studies for application as a PET tracer", Ann. Nuclear Med., Vol. 10, pp. 395-9.

\section{Is inhaled ammonia neurotoxic?}

